\title{
SCREENING OF BC F 1 POPULATION (BG 379-2/ IR 07F102 // BG 379-2) OF RICE (Oryza sativa L.) FOR SUBMERGENCE TOLERANCE USING MOLECULAR MARKERS
}

\author{
R. N. Nawarathna ${ }^{1}$, A. L. T. Perera ${ }^{1}$ and W. L. G. Samarasinghe ${ }^{2}$
}

\begin{abstract}
Rice is susceptible to submergence from germination to early vegetative stage and affects wetland paddy cultivation areas of Sri Lanka is affected by flash floods. There are no submergence tolerant varieties available locally. Therefore, this research was designed to evaluate the $B C_{l} F_{1}$ population (Bg 379-2/ IR 07F102 // Bg 379-2) morphologically for submergence tolerance and to select polymorphic molecular markers between the donor parents IR07F102 and recurrent parent, Bg 379-2, and to screen and select plants of the $B C_{I} F_{I}$ population for submergence tolerance using identified molecular markers. The 108 individuals of $B C_{1} F_{1}$ of rice were morphologically screened for plant lodging, leaf senescence and plant elongation and molecular screening was done by using 5 Rice microsatellites and 1 In Del marker. Out of those, molecular marker, RM464A for SUB1 gene conferring submergence tolerance, was used to screen the $B C_{I} F_{1}$ population. Five plants were selected as submergence tolerant individuals as they were positive in both morphological and molecular screening.
\end{abstract}

Keywords: Molecular markers, Rice (Oryza sativa L.), Submergence tolerance

\section{INTRODUCTION}

Rice (Oryza sativa L.), is one of the major cereals grown worldwide and also the staple food of the people of Asia and Sri Lanka. Rice is mainly grown as a wetland crop due to its semi-aquatic nature and ability to survive in water logged soils, however the vegetative stage of the plant is highly susceptible to submergence caused by flash floods of $50 \mathrm{~cm}$ or more during heavy monsoon rains (Mackill et al., 1996). Most rain-fed submergenceprone rice lands located in wet zone of Sri Lanka receive a mean annual rainfall of more than $2500 \mathrm{~mm}$. Flash floods, a rapid surge of flooding that subsides after several $\mathrm{d}$ and lasts no longer than $10 \mathrm{~d}$, are common phenomena in the Kalutara, Gampaha, Ratnapura and Matara districts and around 75,000 ha of low lying lands of coastal flood plains located from Wennappuwa to Dondra remain unproductive due to poor drainage and long term submergence as a result of accumulation of runoff and flowing of rivers (Jayawardena, 1984).

Sensitive rice cultivars die within a week under complete submergence conditions. Even if the plant is only partially submerged, it reduces tillering, induces rapid elongation of shoots and increases lodging (Pereta, 2007). Most of the currently recommended high yielding rice varieties are not tolerant to submergence. This affects most of the farmers in Low Country Wet Zone (LCWZ), therefore, many farmers cultivate submergence tolerant, photosensitive traditional varieties such as "Ma wee", "Madael", "Thavalu”, 'Molligoda', and 'Soola' in order to cope with submergence. However, these local traditional varieties generate poor yields of 0.75 to $1.0 \mathrm{t} / \mathrm{ha}$ (Jayawardena, 1984).

\footnotetext{
2 Rice Research and Development Institute (RRDI), Batalagoda, Sri Lanka.
} 
In 1996, a major QTL SUBMERGENCE 1 (SUB1) was mapped on chromosome9 of indica rice line, IR 4093 1-26 (Xu and Mackill, 1996). This QTL contributes to $70 \%$ of phenotypic variation together with minor QTLs located on chromosomes $1,2,6,7,8,10,11$ and 12 in tolerant low land rice cultivars (Nandi et al., 1997; Toojinda et al.,2003). Mapping of SUB1 facilitates the improvement of submergence tolerant cultivars through Marker Assisted Backcrossing (MAB) (Neereja et al., 2007).

The requirement for developing submergence tolerant, high yielding rice varieties has been identified as an urgent need of national importance. The objectives of this research was to meet this challenge by using molecular markers to screen a $\mathrm{BC}_{1} \mathrm{~F}_{1}$ population of the cross between exotic line IR07F102 having flood tolerance QTL, SUB1 and the local susceptible variety, $B g$ 379-2 in order to obtain a flood tolerant line.

\section{MATERIALS AND METHODS}

The examined population comprised of 108 $\mathrm{BC}_{1} \mathrm{~F}_{1}$ plants and 25 plants of each of the tolerant parent, IR 07F102 and recurrent parent, $B g$ 379-2 a local variety susceptible to submergence. The seeds were provided by Rice Research and Development Institute (RRDI), Batalagoda, Sri Lanka.

\section{Morphological screening}

A total of 108, two-week old seedlings of $\mathrm{BC}_{1} \mathrm{~F}_{1}$ population were morphologically screened together with the parents by following a slightly modified version of Vergera and Mazaredo method as followed by Septiningsih et al., (2009) at RRDI, Batalagoda. They were submerged in $58 \mathrm{~cm}$ of water for $14 \mathrm{~d}$ under water temperature of $33.52^{\circ} \mathrm{C}$. The desubmerged plants were scored from $3 \mathrm{~d}$ after de-submergence up to $14 \mathrm{~d}$ of recovery for Plant Elongation (PE), Leaf Senescence (LS) and Lodging.
Plant height and height of sheath were measured from soil level up to the tip of longest leaf before submergence, 6 days after submergence and 3 days after de-submergence using a meter ruler. The colour of leaves and thickness of stem were recorded by visual observation after 3 days from de-submergence up to 14 days of recovery. The responses of plants were scored for lodging using a scale developed by GSR project of IRRI with slight modifications as shown in Table 01 .

\section{Molecular screening}

DNA was extracted from 10-day old leaf tissues by using a rapid DNA extraction protocol (Anushka et al., 2008). The PCR analysis was carried out by using 6 rice microsatellite primers (RM219, RM464A, RM23869, RM316, RM285, RM105) and one In Del primer (ART5) (Integrated DNA Technologies, Coralville, LA, USA).

The PCR was performed in a mixture of $15 \mu \mathrm{L}$ containing $3 \mu \mathrm{L}$ of template DNA, $3 \mu \mathrm{L}$ of $5 \mathrm{X}$ PCR buffer (100 mM Tris-HCl (pH 8.3), 250 $\mathrm{mM} \mathrm{KCl}), 0.9 \mu \mathrm{L}$ of $25 \mathrm{mM} \mathrm{MgCl}, 0.15 \mu \mathrm{L}$ of $10 \mathrm{mM}$ dNTPs, $1 \mu \mathrm{L}$ each of $5 \mu \mathrm{M}$ Forward primer and Reverse primer and $0.2 \mu \mathrm{L}$ Taq DNA polymerase $(5 \mathrm{U} / \mu \mathrm{L})$ (Promega BioSciences, CA, USA). After initial denaturation for $5 \mathrm{~min}$ at $94{ }^{\circ} \mathrm{C}$, PCR was carried out with a profile of 35 cycles at $94{ }^{\circ} \mathrm{C}$ for $1 \mathrm{~min}, 59.1^{\circ} \mathrm{C}$ for $1 \mathrm{~min}$, $72{ }^{\circ} \mathrm{C}$ for 2 min with a final extension at $72{ }^{\circ} \mathrm{C}$ for 5 min and a hold at $4{ }^{\circ} \mathrm{C}$ using My cycler (BIORAD laboratories, CA, USA). The PCR products were analyzed in $8 \%$ polyacrylamide gels for $6.15 \mathrm{hr}$ at $100 \mathrm{~V}$ using vertical gel electrophoresis (Life Technologies, Paisley, Scotland).

\section{RESULTS AND DISCUSSION}

Submergence tolerance was assessed using the investigated morphological parameters independently. Morphological screening was carried out in order to test the relationship of morphological traits such as LS, PE 
and lodging with submergence tolerance. In addition, 28 plants of lodging index 1 and Accordingly a total of 32 plants which 2 upon desubmergence were considered as elongated less than $12 \mathrm{~cm}$ under submergence tolerant (Figure 03). The plant numbers 52, were considered submergence tolerant (Figure 72,97, 116, 64, 15, 98 and 49 were positive for 01) and 25 plants that retained dark green all three traits in the morphological screening. leaves under submergence were also selected as tolerant (Figure 02).

Table 01. Plants selected in screening

\begin{tabular}{|c|c|c|c|c|c|c|c|c|c|}
\hline \multirow{2}{*}{$\begin{array}{l}\text { Plant } \\
\text { no }\end{array}$} & \multicolumn{3}{|c|}{$\begin{array}{l}\text { Morphological } \\
\text { Screening }\end{array}$} & \multirow{2}{*}{$\begin{array}{l}\text { Molecular } \\
\text { Screening }\end{array}$} & \multirow{2}{*}{$\begin{array}{l}\text { Plant } \\
\text { no }\end{array}$} & \multicolumn{3}{|c|}{$\begin{array}{l}\text { Morphological } \\
\text { Screening }\end{array}$} & \multirow{2}{*}{$\begin{array}{l}\text { Molecula } \\
\text { Screening }\end{array}$} \\
\hline & E & L S & $\mathrm{L}$ & & & E & L S & $\mathrm{L}$ & \\
\hline 33 & - & + & - & - & 28 & - & + & + & - \\
\hline 50 & + & + & - & - & 96 & - & - & + & - \\
\hline 63 & + & + & - & - & 47 & + & - & + & - \\
\hline$* 52$ & + & + & + & + & 95 & - & - & + & + \\
\hline 118 & + & - & - & - & 25 & - & + & - & - \\
\hline 82 & - & - & - & + & 11 & - & - & + & + \\
\hline 2 & + & - & - & - & 71 & - & - & + & - \\
\hline 78 & - & - & + & - & 127 & - & - & + & - \\
\hline 130 & - & + & - & - & 4 & - & - & + & + \\
\hline 44 & + & - & - & - & 98 & + & + & + & - \\
\hline 74 & + & - & - & - & $* 49$ & + & + & + & + \\
\hline 54 & + & - & - & - & 134 & + & - & - & - \\
\hline 51 & - & + & - & - & 55 & + & - & + & - \\
\hline 69 & - & + & + & - & 79 & + & - & + & - \\
\hline$* 72$ & + & + & + & + & 67 & + & - & + & - \\
\hline$* 97$ & + & + & + & + & 61 & + & - & - & - \\
\hline 5 & + & - & - & - & 77 & - & - & - & + \\
\hline 16 & + & - & - & - & 64 & + & + & + & - \\
\hline 57 & + & + & - & - & 34 & - & + & + & - \\
\hline 113 & + & + & - & + & 40 & + & - & + & - \\
\hline 119 & - & + & + & - & 43 & - & - & + & - \\
\hline 30 & + & - & - & - & 66 & + & + & - & - \\
\hline 15 & + & + & + & - & 10 & + & - & + & - \\
\hline 110 & - & - & - & + & 68 & - & + & - & - \\
\hline 84 & + & - & - & - & 88 & - & + & - & - \\
\hline 87 & + & - & - & - & 126 & - & + & + & - \\
\hline 125 & + & - & - & - & 133 & - & - & + & - \\
\hline 104 & - & - & - & + & 38 & - & - & - & + \\
\hline$* 116$ & + & + & + & + & 13 & - & + & - & - \\
\hline
\end{tabular}

$(+)=$ Selected,$(-)=$ Not Selected, $E=$ Elongation, $L S=$ Leaf Senescence, $L=$ Lodging, $*=$ Selected in both molecular and morphological screening 

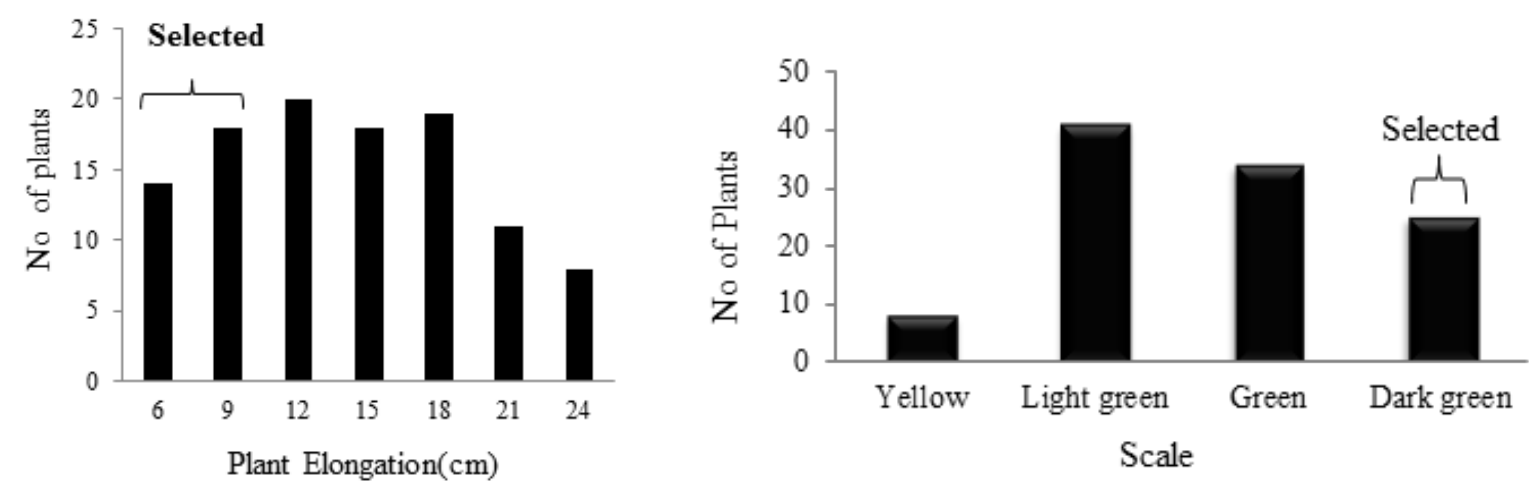

Figure 01: Distribution pattern for plant elongation of $\mathrm{BC}_{1} \mathrm{~F}_{1}$ population of $\mathrm{Bg}$ 379-2/ IR 07F102 Bg 379-2.

Figure 02: Distribution pattern of leaf senescence of $\mathrm{BC}_{1} \mathrm{~F}_{1}$ population of $\mathrm{Bg}$ 379-2/ IR 07F102 // Bg 379-2.

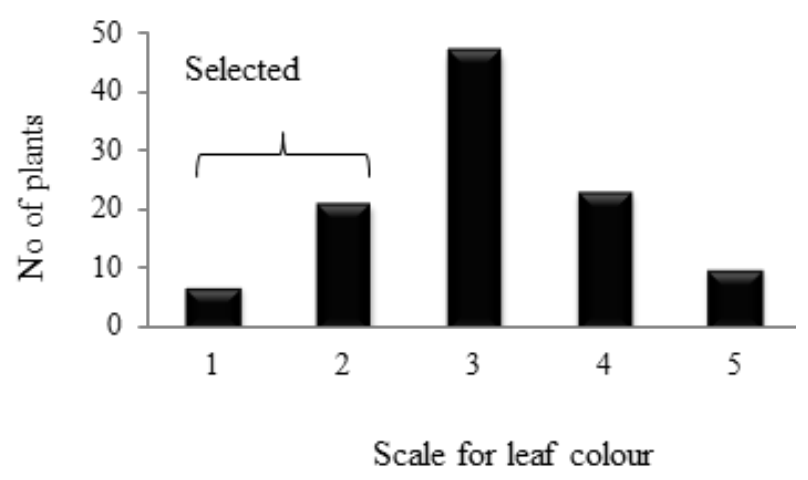

Figure 03: Distribution pattern for lodging scores of $\mathrm{BC}_{1} \mathrm{~F}_{1}$ population of $\mathrm{Bg}$ 379-2/ IR 07F102 // Bg 379-2 ; 1-5: 1= No lodging, 2= Slightly lodged, 3= Moderately lodged, $4=$ Nearly lodged, $5=$ Completely lodged.

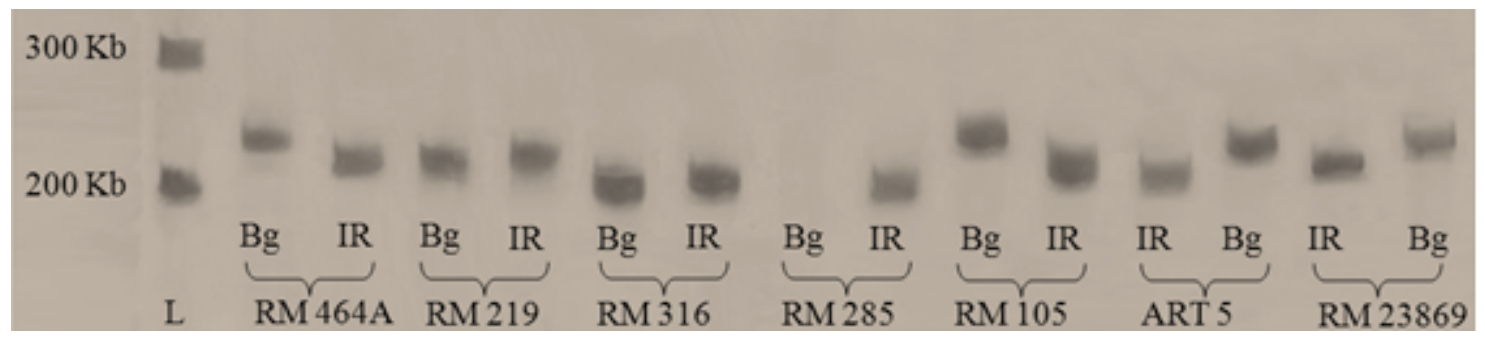

Figure 04: PCR products of parents to check for polymorphic markers ; $L=100 \mathrm{bp}$ ladder, $B g=B g$ 379-2, IR= IR 07F102. 


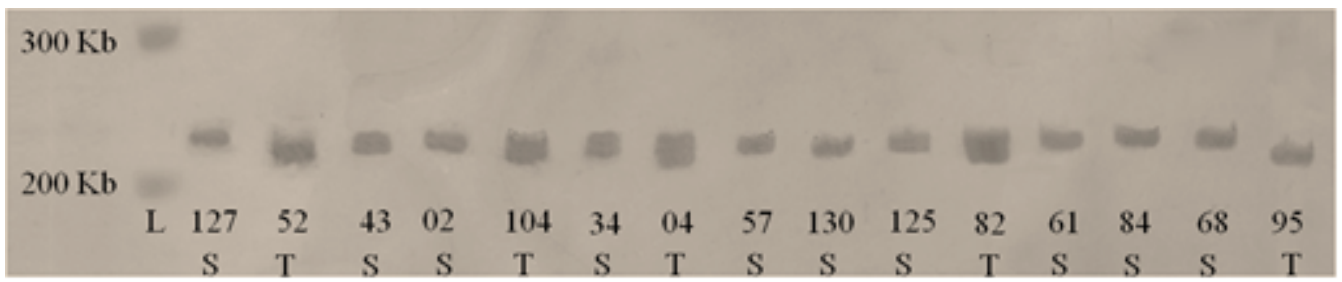

Figure 05: Amplified products of randomly selected individuals of $\mathrm{BC}_{1} \mathrm{~F}_{1}$ population of Bg 379-2/ IR 07F102 // Bg 379-2 by RM 464A; $S=$ Susceptible, T= Tolerant, $L=$ 100bp ladder ; 127, 52, 43, 02, 104, 34, 04, 57, 130, 125, 82, 61, 84, 68, 95 = Plant numbers of $\mathrm{BC}_{1} \mathrm{~F}_{1}$ individuals .

Individuals of $\mathrm{BC}_{1} \mathrm{~F}_{1}$ population showed significant variation in terms of PE (Figure 01 ) and ranged from $6 \mathrm{~cm}$ to $24 \mathrm{~cm}$. Some individuals of $\mathrm{BC}_{1} \mathrm{~F}_{1}$ showed rapid elongation of first two leaves compared to tolerant parent after $2 \mathrm{~d}$ of submergence (data not shown) and attempted to escape stress by reaching the surface of water column with their leaf tips, in order to utilize atmospheric oxygen. However, plants which showed higher initial PE accompanied by LS collapsed upon desubmergence. This showed that a combination of moderate submergence tolerance and moderate elongation ability may be desirable under stagnant long-term partial flooding. Therefore, the plants which showed lower PE together with plants categorized under lodging scales of 1 and 2 which remained erect were considered as tolerant individuals. Because of vigorous plants having erected stature with lower elongation of sheaths and leaves can escape from submergence stress during vegetative stages can withstand submergence and bear heavy panicles at the reproductive stage (Mackill et al., 1996).

Plants were selected against LS, since photosynthesis is affected by LS and survival of plant is greatly determined by degree of resistance to LS. Therefore, high chlorophyll content in plants which remained green may add to survival over other susceptible individuals.
Molecular screening was carried out to identify plants carrying $S U B 1$ gene in order to precise identification of $\mathrm{BC}_{1} \mathrm{~F}_{1}$ plants to carry out breeding programmes. Out of tested markers, RM464A, RM 105, RM 23869 and ART 5 showed polymorphism between the parents, IR07F102 and Bg 379-2 in 8\% polyacrylamide gel (Figure 04).

From these, the tightly linked marker RM464A was used to screen the $\mathrm{BC}_{1} \mathrm{~F}_{1}$ population (Figure 05) and intogression of $S U B 1$ was assured by tightly linked marker RM 464A.

A total of $14 \mathrm{BC}_{1} \mathrm{~F}_{1}$ plants of number $4,52,82$, $72,97,113,49,110,11,77,104,116,95$ and 38 were selected by molecular screening based on their heterozygous nature for presence of SUB1.

The 5 plants 72, 52, 97, 116 and 49 were selected as submergence tolerant in both morphological and molecular screening (Table 02).

Amplicons for $S U B 1$ is identified with sizes between $200 \mathrm{~kb}$ and $300 \mathrm{~kb}$ for all checked markers. $\mathrm{Xu}$ et al., (2004) found that rice microsatellite markers, RM464A linked to SUB1 by $0.7 \mathrm{cM}$ can be used for foreground selection of the Sub1 over wide range of recipients due to lower recombination events between marker and QTL to enhance precision. Therefore, intogression of $S U B 1$ locus was assured by tightly linked marker, RM 464A 
as suggested by $\mathrm{Xu}$ et al., (2004). Identified polymorphic In Del marker, ART 5 which targets $15 \mathrm{bp}$ insertion in promoter region of $S U B 1 C$ is a potential marker to use together with $S U B 1 A$ markers in final screening, to ensure the introgression of both $S U B 1 A$ and $S U B 1 C$ into newly developed submerges tolerant lines.

Though breeding for submergence has been initiated since $1980 \mathrm{~s}$, this is the first attempt on intogression of SUB1 into local new improved variety via MAS in Sri Lanka. Improvement for both abiotic stresses such as drought, salinity, iron toxicity and biotic stresses together with submergence tolerance is essential in rice breeding programmes to address the rising food demand in Sri Lanka.

\section{CONCLUSION}

In summary, five plants from the $\mathrm{BC}_{1} \mathrm{~F}_{1}$ population derived from $\mathrm{Bg} 379-2 /$ IR 07F102 // Bg 379-2 were selected for submergence tolerance considering both morphological and molecular traits. The polymorphic marker, RM 464A can be used in MAS to cope with flash floods to mitigate the impact of climate change in rice production in Sri Lanka.

\section{REFERENCES}

Anushka, K., Kottearachchi, N. S. and Attanayake, D. P. S. T. G. (2008). Identification of fragrance gene $(f g r)$ in Sri Lankan Rice varieties using polymerace chain reaction based Molecular markers. In: Proceedings of $8^{\text {th }}$ Agricultural symposium. Volume 8 . (Jayasekera, S. J. B. A., Attanayaka, D. P. S. T. G., Kelaniyangoda, D. B., Atauda, A. M. T. P., Weerakkody, W. J. S. K., Abeysinghe, D. C., Jayasinghe-Mudalige, U. K., .Yakandawala, K. and Kottearchchi, N. S. Eds.).Wayamba University of Sri Lanka, Makandura, Gonawila, Sri Lanka. 182-187.

Jayawardena, S. D. J. (1984). Rice cultivation in the tidal swamps of Sri Lanka. In: Workshop on research priorities in tidal swamp rice. (Annonymous Eds.). International Rice Research Institute, Manila, Phillipines. 107-113.

Mackill, D. J. , Coffman, W.R. and Garrity, D. P. (1996). Rainfed lowland rice improvement. 1st Edition. International Rice Research Institute, Manila, Phillipines. 111-125.

Nandi, S., Subudhi, P. K., Senadhira, D., Manigbas, N. L., Mandi, S. S. and Huang, N. (1997). Mapping QTLs for submergence tolerance in rice by AFLP analysis and selective genotyping. Molecular and General Genetics. 255: 1 - 8.

Neeraja, C., Rodriguez, R. M., Pamplona, A., Heuer, S., Collard, B. and Septiningish, E. (2007). A marker-assisted backcross approach for developing submergence-tolerant rice cultivars. Theoretical and Applied Genetics. 115:767 - 776.

Perata, P. and Voesenek, L. A. C. J. (2007). Submergence tolerance in rice requires Sub1A, an ethylene-response-factor-like gene. Trends in Plant Science. 12: 43 - 46.

Septiningsih, E. M., Pamplona, A. M., Sanchez, D. L., Neeraja, C. N., Vergara, G. V., Heuer, S., Ismail, A. M and Mackill, D .J. (2009). Development of submergence tolerant rice cultivars: the Sub1 locus and beyond. Annals of Botany.103: 151-160. 
Toojinda, T., Siangliw, M., Tragroonrung, S. and Vanavichit, A. (2003) . Molecular genetics of submergence tolerance in rice: QTL analysis of key traits. Annals of Botany. 91:243 $-253$.

$\mathrm{Xu}, \mathrm{K}$. and Mackill, D. J. (1996). A major locus for submergence tolerance mapped on rice chromosome 9. Molecular Breeding. 2: 219 - 224.

Xu, K., Deb, R. and Mackill, D. J. (2004). A Microsatellite marker and codominant PCR-based marker for marker assisted selection of submergence tolerance in rice. Crop science. 44: 248- 253. 